\title{
GEOGRAFIA HUMANISTA: HISTÓRIA, CONCEITOS E O USO DA PAISAGEM PERCEBIDA COMO PERSPECTIVA DE ESTUDO
}

\author{
Humanistic Geography: history, concepts and \\ the use of the perceived landscape \\ as a perspective of study
}

\author{
Samir Alexandre ROCHA ${ }^{1}$
}

\begin{abstract}
RESUMO
O conhecimento geográfico transformou-se e continua sendo construído, tendo sua estruturação discutida e reelaborada a partir do surgimento de novas idéias e debates que resultam em diferentes formas de pensamento e, por fim, novas perspectivas de estudo. Realizado com base em pesquisa bibliográfica, o presente artigo tem como objetivo apresentar um histórico de como se desenvolveu a construção da perspectiva de estudo geográfico que é a Geografia Humanista, destacando seus princípios conceituais e metodológicos, apresentando e discutindo como é realizada a leitura da paisagem com base nessa linha de pensamento.
\end{abstract}

\section{Palavras-chave:}

Geografia Humanista; fenomenologia; paisagem e percepção.

\begin{abstract}
The geographic knowledge has been changed and continues to be constructed, having its structure discussed and re-elaborated from the sprout of new ideas and debates that result in different forms of thought and, finally, new study perspectives. It was carried through on the basis of bibliographical research, the present article aims at developing and devising a description of how has developed the construction of the perspective of geographic study that is Humanistic Geography, detaching its conceptual and methodological principles, presenting and arguing as the reading of the landscape with base in this line of thought is carried through.
\end{abstract}

\section{Key words:}

Humanistic Geography; phenomenology; landscape and perception. 
ROCHA, S. A. Geografia Humanista: história, conceito e o uso da paisagem...

\section{INTRODUÇÃO}

Ao longo dos tempos, a Geografia se mostrou como um campo do conhecimento que busca constantemente a compreensão do mundo e suas contradições no âmago das relações sociais, na apropriação e uso do meio ambiente.

Nesse sentido, ao longo do seu processo de desenvolvimento e construção evidenciam-se diferentes formas de perceber, pensar e refletir os fenômenos socioespaciais, sendo cada uma das quais geradoras de linhas metodológicas as quais são fundamentais no processo de construção do conhecimento geográfico. Surgem assim linhas denominadas, por exemplo, como Geografia Pragmática ou Teorética, Geografia Radical ou Crítica, entre outras.

Com base nesse fato, este artigo propõe-se a destacar como se iniciou e se desenvolveu uma dessas linhas de pensamento, que é a Geografia Humanista, destacando o seu processo histórico, seus princípios conceituais e metodológicos, e apresentando como é realizada a leitura da paisagem sob essa perspectiva.

Assim, o presente artigo inicia-se com a apresentação da construção da Geografia Humanista ao logo da história, seguindo para a fenomenologia como aporte dessa perspectiva de estudo e, por fim, apresenta a paisagem e percepção como processos e relações interdependentes nessa linha de pensamento.

\section{A GEOGRAFIA HUMANISTA E SUA CONSTRUÇÃO AO LONGO DA HISTÓRIA}

Pensando a Geografia atual como uma ciência que busca a compreensão das relações socioespaciais, há de se entender que as maneiras de se analisar estes processos assumem diferentes formas ao longo do tempo, a partir de um contexto de conhecimento que, como citado por Carlos (2002, p. 162), “(...) é cumulativo (histórico), social (dinâmico), relativo e desigual, ao mesmo tempo contínuo/descontínuo".

Buscando realizar uma breve exposição acerca dessa questão, há que se destacar que a Geografia surge na Antigüidade tendo como objetivo determinar coordenadas com a finalidade de localizar os lugares na superfície da Terra, gerando assim representações espaciais cartográficas dos lugares e, de forma secundária, descrições sobre os mesmos, como acentua Claval (1997, p. 2002).
Com as explorações marítimas do século $\mathrm{XVI}$, o trabalho do geógrafo passa por uma grande transformação que, embora mantivesse associação com o seu objetivo central, sendo que esse período foi fundamental para que outras mudanças ocorressem em relação à Geografia. Era essa uma fase na qual o melhor conhecimento das rotas náuticas constituía-se como fator essencial no sucesso de grandes empreitadas econômicas, sendo o trabalho do geógrafo, nesse sentido, intensificado no estabelecimento de latitudes e longitudes, associando leituras de documentos de viagem a levantamentos astronômicos. (CLAVAL, 1997)

Assim, esse período marca a função da Geografia como um conhecimento fundamental, tendo em vista que os Estados Ocidentais entendiam que, a partir da maior ciência quanto às melhores rotas marítimas, poderiam obter maiores lucros com menores riscos, promovendo assim amplos investimentos, especialmente nos estudos cartográficos.

Contudo, com base nesses investimentos que dão origem à criação e ao estabelecimento de equipamentos de navegação, a Geografia passa a ser questionada, tendo em vista a figura profissional cada vez mais reforçada do cartógrafo, fazendo com que muitos pesquisadores e estudiosos da área ingressem em uma nova perspectiva de trabalho associada em determinados aspectos às ciências naturalistas, atuando em uma atividade até então secundária que era a descrição dos espaços.

Nessa nova forma de trabalho, um naturalista que se destaca, sobretudo na apresentação das paisagens, é Alexander von Humboldt, pesquisador que enfatiza em seus trabalhos a necessidade de se praticar observações e descrições cuidadosas e precisas da natureza no campo, demonstrando amplo interesse por aspectos como fisionomia e aspectos da vegetação, as influências do clima sobre os seres, etc. (AMORIM FILHO, 1998; MAXIMIANO, 2004)

A partir desse momento histórico, duas concepções se destacam na Geografia: uma primeira, que buscava por meio de seus métodos o entendimento das relações entre a natureza e a sociedade, e uma segunda, que tinha como preocupação o papel dos espaços no funcionamento dos grupos, tendo as duas linhas em comum a convicção sobre a existência de uma realidade global. (AMORIM FILHO, 1998)

Nesse sentido, com maior ênfase no final do século XIX até a metade do século XX, é proposta uma nova teoria de diferenciação regional da Terra, baseada na existência de combinações de aspectos naturais e de 
ROCHA, S. A. Geografia Humanista: história, conceito e o uso da paisagem...

artefatos comuns em dados espaços como resultante da ação conjugada das forças naturais e da ação humana, sendo exemplo as regiões agrícolas, industriais, turísticas, históricas, etc. Após essa evolução um novo enfoque surge na Geografia, que é o estudo da distribuição dos homens e sua inserção no meio ambiente, passando os grupos humanos a ser o centro da análise. (CLAVAL, 1997, 2002)

Assim, a partir de autores como Carl Sauer, é reforçado uma nova linha de pensamento denominada de Geografia Cultural, a qual estava alicerçada em temas tais como história da cultura no espaço, ecologia cultural e, principalmente, paisagens culturais, sofrendo, de acordo com Corrêa (1999), críticas severas relacionadas principalmente a questões conceituais e metodológicas (não se tinha uma metodologia e conceitos de estudo claros), o que gerou uma relativa perda de prestígio e, por fim, o seu declínio na década de 40 .

$\mathrm{Na}$ década de 50, um novo paradigma se apresenta nos estudos geográficos: trata-se do estudo das localizações. Pensando-se assim, o conceito de redes fundamentado na definição de que "O espaço está organizado porque está estruturado em redes de relações sociais e econômicas, em redes de vias de transporte e de comunicação, e em redes urbanas, que concretizam os efeitos da combinação dessas redes" (CLAVAL, 2002 p.18). Nesse sentido, é quebrada a idéia do espaço a partir da visão naturalista, cedendo a uma idéia funcionalista.

Com base nesse momento, surgem no mundo movimentos de discussão que ressaltam e alertam para o fato de que, enquanto área do conhecimento enquadrada nas ciências sociais, a Geografia pouco falava sobre os homens.

Assim, já no início da década de 60 , na busca de uma renovação da Geografia Cultural, a partir das discussões de John K. Wright, David Lowenthal lança trabalhos nos quais discute o fato de que a Geografia deveria abarcar os vários modos de observação, o consciente e o inconsciente, o objetivo e o subjetivo, o fortuito e o deliberado, o literal e o esquemático. (HOLZER, 1996)

Outro pesquisador fundamental é o arquiteto Kevin Lynch, pelo seu trabalho publicado também na década de 60: A imagem da cidade. Segundo Oliveira (2001, p. 19) "(...) enquanto este último, procurando as necessidades práticas do desenho urbano procura desenvolver uma metodologia que possa ser aplicada universalmente, (...) Lowenthal (...) desenvolve uma renovação e ampliação do objeto da Geografia."
Tem-se assim um novo modo de pensar a Geografia, sob um enfoque cultural, no qual a natureza, a sociedade $e$ a cultura são refletidas como fenômenos complexos sobre os quais só se obtém respostas a partir de experiências que se apresentam e conforme o sentido que as pessoas dão à sua existência.

No mesmo período, conforme destacam Serpa (2001) e Holzer (1996), é lançado o livro Topofilia de Yi Fu Tuan, trabalho este no qual o autor, baseado nas obras do filósofo francês Gaston Bachelard, propõem que a Geografia volte-se a um novo pensar sobre a relação do homem com o mundo em que vive.

Outro nome que se destaca nessa discussão éAnne Buttimer. Segundo Oliveira (2001), essa pesquisadora tem uma importância fundamental na constituição da Geografia Humanista, tendo em vista o desenvolvimento de seus trabalhos, que a partir de um olhar crítico tratou de questões sociológicas nos valores geográficos, avaliando as idéias de um ponto de vista filosófico, tecendo considerações sobre o existencialismo e o fenomenologismo no futuro da Geografia.

Somadas às discussões, essa perspectiva despontou como um ressurgimento da perspectiva cultural na Geografia, sendo denominada como uma nova Geografia Cultural ou Geografia Fenomenológica (título indicado por Edward Relph em 1971), Geografia da Percepção, Geografia Humanística ou, enfim, Geografia Humanista. (OLIVEIRA, 2001; SEABRA, 1999; HOLZER, 1992)

Buscando uma maior compreensão dos ideais dessa linha de pensamento, a Geografia Humanista é definida por bases teóricas nas quais são ressaltadas e valorizadas as experiências, os sentimentos, a intuição, a intersubjetividade e a compreensão das pessoas sobre o meio ambiente que habitam, buscando compreender $\mathrm{e}$ valorizar esses aspectos.

A Geografia Humanista procura um entendimento do mundo humano através do estudo das relações das pessoas com a natureza, do seu comportamento geográfico, bem como dos seus sentimentos e idéias a respeito do espaço e do lugar. (TUAN, 1982)

Sob esse prisma de estudo da Geografia, tem-se como premissa que cada indivíduo possui uma percepção do mundo que se expressa diretamente por meio de valores e atitudes para com o meio ambiente, ou, em outras palavras, a Geografia Humanista busca a compreensão do contexto pelo qual a pessoa valoriza e organiza o seu espaço e o seu mundo, e nele se relaciona. 
ROCHA, S. A. Geografia Humanista: história, conceito e o uso da paisagem...

(...) os geógrafos humanistas argumentam que sua abordagem merece o rótulo de "Humanista", pois estudam os aspectos do homem que são mais distintamente humanos: significações, valores, metas e propósitos. (...). Da valorização da percepção e das atitudes decorre a preocupação de verificar os gostos, as preferências, as características e as particularidades dos lugares. Valoriza-se também o contexto ambiental e os aspectos que redundam no encanto e na magia dos lugares, na sua personalidade e distinção. Há o entrelaçamento entre o grupo e o lugar. (ENTRIKIN, 1980, p.16)

Além dos pressupostos da Geografia Humanista há de se ressaltar que, em relação às primeiras proposições de inserção e ressalva sobre a importância da cultura no estudo geográfico, é realizada uma nova reflexão sobre os conceitos, incluindo neste bojo os elaborados, principalmente entre 1925 e 1940, buscando em outras ciências definições teóricas para alicerçar esta linha de pensamento; nesse sentido, elaboraram uma discussão sobre termos como cultura, percepção, mundo-vivido, paisagem, lugar, etc.

Outro aspecto a ser destacado nesse processo de consolidação da Geografia Humanista é o fato de que esta, ao estruturar-se, buscou e estabeleceu para seus estudos um aporte filosófico e conceitual baseado na fenomenologia, procurando assim entender como as atividades e os fenômenos geográficos revelam a qualidade da conscientização humana. (HOLZER, 1999)

Conforme Holzer (1996, p.11-12), a fenomenologia passa a ter a fenomenologia como aporte para estudos geográficos com aspectos subjetivos da espacialidade, a partir de Edward Relph, sendo que "(...) o método fenomenológico seria utilizado para se fazer uma descrição rigorosa do mundo vivido da experiência humana e, com isso, através da intencionalidade, reconhecer as 'essências' da estrutura perceptiva".

Segundo Oliveira (2001), com base nessas discussões há um retorno do interesse pelo estudo das paisagens em outro nível não apenas descritivo ou fotográfico, mas sim com o status de um elemento essencial na leitura urbana.

\section{AFENOMENOLOGIA COMOAPORTE DA GEOGRAFIA HUMANISTA}

A Fenomenologia (...) procura examinar a experiência humana de forma rigorosa, por meio de uma ciência da experiência e reflexão tornando possível observar as coisas tal como elas se manifestam (...).

(ENTRIKIN, 1980)
Uma das idéias base da Geografia, ressaltada, sobretudo, pela Geografia Humanista, é o fato de que a superfície terrestre é constituída por um todo no qual se têm situações variadas, apresentadas tanto nas paisagens naturais e artificializadas com nas comunidades que as compõem. Assim, uma das premissas que regem e que constituem a base da discussão humanista na Geografia refere-se ao princípio das idiossincrasias a respeito dos territórios, paisagens e lugares.

Nesse sentido, há de se refletir sobre toda uma gama de conceitos e princípios que dão base e sustentam a Geografia Humanista como forma de se refletir sobre as relações sociais em relação ao meio ambiente em que se tem fortemente evidenciadas relações culturais, sentimentos; enfim, se apresenta como uma abordagem que busca compreender o espaço geográfico como espaço de vivência. (TUAN, 1980; BUTTIMER, 1982; RELPH, 1975)

As primeiras reflexões sobre a fenomenologia surgem entre o final do século XIX e início do século XX, com a publicação de 1901 sob o título Investigações lógicas; em que a fenomenologia surge intimamente ligada à Matemática. Tendo como idealizador Edmund Husserl, inicia suas reflexões procurando estabelecer uma nova forma de pensamento sobre a lógica, cujo princípio fundamental são as experiências básicas da consciência não interpretadas, tomando como máxima o compreender as coisas em si mesmas. (COBRA, 2004; VON ZUBEN, 2004; MERLEAU-PONTY, 1994)

O termo fenomenologia surge a partir da palavra fenômeno, que, por sua vez é gerada da expressão grega fainomenon, que deriva do verbo fainestai e quer dizer "mostrar-se a si mesmo", representando “(...) tudo aquilo que, do mundo externo, se oferece ao sujeito do conhecimento, através das estruturas cognitivas da consciência". (SERPA, 2001)

Logo, a fenomenologia busca aquilo que se apresenta como o princípio básico do pensamento filosófico, que é ampliar incessantemente a compreensão da realidade, no sentido de apreendê-la na sua totalidade, destacando a importância das percepções, dos fatos socioambientais, e por fim da intersubjetividade do pensamento, que, como um todo, constitui nosso mundo-vivido, o qual envolve as histórias, os sentimentos, os valores, etc.

A fenomenologia tem a ver com os princípios e as origens do significado e da experiência. É concernente a fenômenos tais como ansiedade, comportamento, conduta, religião, lugar e topofilia, que não podem 
ROCHA, S. A. Geografia Humanista: história, conceito e o uso da paisagem...

ser compreendidos somente através da observação e medição, mas que devem primeiro ser vividos para serem compreendidos como eles realmente são, como ressalta Tuan (1980).

Visa, de acordo com Garnica (1997), a compreensão, o conhecimento do mundo, sendo que, ao "voltar-se às coisas mesmas", busca promover reflexões sobre a importância das experiências vividas, apelando por descrições mais concretas do espaço e do tempo, e de seus significados na vida humana diária, deixando assim transparecer as essências que constituem os seus fenômenos.

Logo, ela pode ser definida como "(...) um modo filosófico de reflexão a respeito da experiência consciente e uma tentativa para explicar isso em termos de significado e significância" (BUTTIMER, 1982, p. 170), havendo esforços para, por meio do uso dessa metodologia na Geografia, se elucidar o mundo enquanto espaço vivido e de vivência a partir do qual o homem, habitante de um mundo físico e social, influi diretamente sobre os significados e as intencionalidades de sua consciência, onde são construídas e estabelecidas as experiências, fato que envolve, portanto, mais do que apenas compreensões cognitivas, sendo o espaço um conjunto contínuo e dinâmico onde o experimentador vive, se desloca, percebe e valoriza as coisas buscando atribuir-lhes significados.

Tem-se assim como preceito o fato de que as pessoas estão diretamente ligadas ao mundo através de sua vivência e de seus sentidos, onde cada indivíduo vê, ou melhor, percebe a realidade de forma diferente, sendo cada idéia sobre esse espaço composta de uma consciência baseada em experiências pessoais, aprendizados, imaginação, memória, fatos que tornam o mundo e o espaço geográfico idiossincrático a partir das percepções humanas sobre ele, mas que, no entanto, não invalidam a afirmação de que todos os seres humanos compartilham de determinadas percepções comuns tendo em vista a vivência em um mundo comum. (BUTTIMER, 1982; LOWENTHAL, 1982; RELPH, 1975; TUAN, 1980)

É nessa perspectiva que o mundo-vivido surge como um conceito-chave definido pela apresentação de um todo composto "(...) de ambigüidades, comprometimentos e significados no qual estamos inextricavelmente envolvidos em nossas vidas diárias (...)" (RELPH, 1975, p. 3).

Mundo, para o fenomenologista, é o contexto dentro do qual a consciência é revelada. Não é um mero mundo de fatos e negócios... mas um mundo de valores, de bens, um mundo prático. Está ancorado num passado e direcionado para um futuro; é um horizonte compartilhado, embora cada indivíduo possa construílo de um modo singularmente pessoal. (BUTTIMER, 1982, p.172)
Assim, conforme Holzer (1997), a Geografia Humanista entende o espaço como o resultado obtido a partir de paisagens marcadas, construídas e constituídas de vontades, valores e memórias, as quais são baseadas em experiências do mundo, referências sociais e redes de interação, resultando assim esse conhecimento no entendimento geográfico do mundo e do autoconhecimento humano em relação aos seus sentimentos sobre o seu meio ambiente, sendo ressaltado que o espaço e, sobretudo, o mundo-vivido, não se apresenta necessariamente como um todo homogêneo ou como uma confusão constituída a partir de várias atividades individuais, mas sim que ele possui maior ou menor grau de ordem e compreensibilidade a partir do seu observador.

Por fim, os geógrafos humanistas assumem como objetivo em seus estudos, ou melhor, “(...) sua pretensão é de relacionar de uma maneira holística o homem e seu ambiente ou, mais genericamente, o sujeito e o objeto, fazendo uma ciência fenomenológica que extraia das essências a sua matéria-prima" (HOLZER, 1997, p. 77).

\begin{abstract}
A Geografia Humanista trouxe novas luzes e abriu novas possibilidades para a compreensão de se encontrar as respostas para a construção de valores e atitudes para se enfrentar os novos desafios que se instalam a cada momento. Os desafios atuais são: a crença infalível na ciência e na tecnologia; a coletividade baseada nos pressupostos insensíveis nas estruturas sociais; e erguer um edifício fundamentado na nova ética das relações humanas e ambientais. (OLIVEIRA, 2001)
\end{abstract}

\section{PAISAGEM E PERCEPÇÃO: PROCESSOS E RELAÇÕES INTERDEPENDENTES}

(...) qualquer paisagem é composta não apenas por aquilo que está à frente dos nossos olhos, mas também por aquilo que se esconde em nossas mentes. (MEINIG, 2002, p. 35)

Embora seja fato que desde o início da história humana estes e as paisagens sejam inseparáveis como expressão de vivência, o termo paisagem começa a ser refletido somente a partir de pensadores como Aristóteles, quando a humanidade passa a perceber e questionar o fato de que sem formas o mundo não existe, passando assim a conceber a Terra como um ambiente composto por elementos naturais e construído.

Com os artistas (especialmente a partir do Renascimento, com exacerbação no Romantismo), o conceito de paisagem começa a sofrer um processo de definição e de análise tendo como interpretação essencial o conceito de 
ROCHA, S. A. Geografia Humanista: história, conceito e o uso da paisagem...

que paisagem significava mais um modo de ver do que de agir, ou, em outras palavras, consolidava-se como uma realidade espaço-visual. (YÁZIGI, 2001)

Com o surgimento da fotografia, e principalmente do cinema, as paisagens passam a ser difundidas de forma mais ampla, gerando uma série de debates, tendo em vista que, se passa a ter uma nova expressão, que não é mais apenas estática, possui movimento ao relacionar história e imagem, associando assim aspectos que anteriormente eram presentes de forma dissociada na pintura e na literatura. (YÁZIGI, 2001)

Paralelamente a esse processo estava a Geografia, contrapondo-se ao subjetivismo exposto pelos artistas com uma preocupação científica de análise, tendo como pretensão a elaboração de conceitos generalizáveis. Mas deparava-se com uma grande dificuldade, pois a princípio não havia um reconhecimento da importância do fator cultural como modificador dos cenários.

Nesse sentido, tem destaque na aplicação do termo paisagem como conceito geográfico Alexander Von Humbold, que o introduz como definição central em seus estudos. Desde então a paisagem passa por uma série de transformações as quais seguem até a atualidade, do que decorre divergência quanto ao seu uso, mesmo na ciência geográfica, como analisa Holzer (1999).

Assim, uma reflexão que marca o processo de construção do pensamento geográfico reside no fato de que:

(...) toda paisagem tem uma identidade que é baseada na constituição reconhecível, limites e relações genéricas com outras paisagens, que constituem um sistema geral. Sua estrutura e função são determinadas por formas integrantes e dependentes. A paisagem é considerada, portanto em certo sentido, como tendo uma qualidade orgânica. (SAUER, 1998, p. 23)

Essa reflexão, realizada por Carl Sauer em 1925, constituiu assim um dos pilares para o estabelecimento e discussão em torno das culturas na Geografia, sendo que a partir de então a paisagem é referenciada não mais apenas como uma cena contemplada por um observador, mas da percepção de diversas cenas individuais; ou seja, constata-se que toda paisagem possui individualidade e ao mesmo tempo relaciona-se com outras paisagens.

Nesse sentido, tem destaque o fato de que:

(...) cada percepção tende a ser seletiva, criativa, fugaz, inexata, generalizada, estereotipada e, justamente porque imprecisa, as impressões parcialmente heterogêneas sobre o mundo em geral sempre são mais convenientes do que os detalhes exatos a propósito de um pequeno segmento do mundo. (LOWENTHAL, 1982, p. 122)
Logo, tem-se evidenciado o fato de que cada visão do mundo é única, pois cada pessoa habita, escolhe e reage ao meio de diferentes maneiras, influenciadas pelos seus sentimentos, visões particulares, e, sobretudo, contemplando as paisagens com suas imagens particulares, o que Tuan (1980) cita como um estenderse para o mundo.

Assim, considera-se a percepção como uma atividade mental de interação do indivíduo com o meio ambiente que ocorre através de mecanismos perceptivos (visão, audição, tato, olfato e paladar) e cognitivos (que envolvem a inteligência, incluindo como motivações humores, conhecimentos prévios, valores, expectativas). É, portanto, essencial para que se desenvolva uma maior compreensão das inter-relações entre o homem e o meio ambiente a partir das suas expectativas, julgamentos e condutas com relação tanto às paisagens naturais como também às construídas; faz emergir a qualidade de vida das populações, e a satisfação do indivíduo com o seu meio ambiente.

Com base no exposto, Del Rio (1999) desenvolveu um esquema explicativo sobre o processo perceptivo aqui adaptado e exposto a seguir. (Figura 1)

Diante disso, para que se tenha uma compreensão da paisagem, é fundamental o entendimento de que a sua dimensão é resultado da percepção que chega aos sentidos, pois a mesma se define como "o que nossa visão alcança (...) não sendo formada apenas por volumes, mas também de cores, movimentos, odores, sons, etc." (SANTOS, 1997, p. 61), ou seja, não se pode falar de paisagem a não ser a partir de sua percepção.

(...) a paisagem se define como espaço ao alcance do olhar, mas também à disposição do corpo; ela se reveste de significados ligados a todos os comportamentos possíveis do sujeito. (...) O corpo torna-se o eixo de uma verdadeira organização semântica do espaço que tem por base oposições como: alto-baixo, direita-esquerda, frente-atrás, próximo-distante (...). (COLLOT, 1990, p.27-28)

Outro princípio a se compreender no processo de percepção da paisagem reside no fato de que esta é marcada e representa processos de transformação cultural, o que implica dizer que ela é uma representação da relação homem/natureza.

Um termo também importante no estudo geográfico da paisagem é a definição de topofilia, que representa os laços afetivos dos seres humanos com o meio ambiente imbuídos de sentimentos como afetividade $\mathrm{e}$ confortabilidade.

Assim, Tuan definiu: 
ROCHA, S. A. Geografia Humanista: história, conceito e o uso da paisagem...

\section{FIGURA 1 - ESQUEMA TEÓRICO DO PROCESSO PERCEPTIVO}

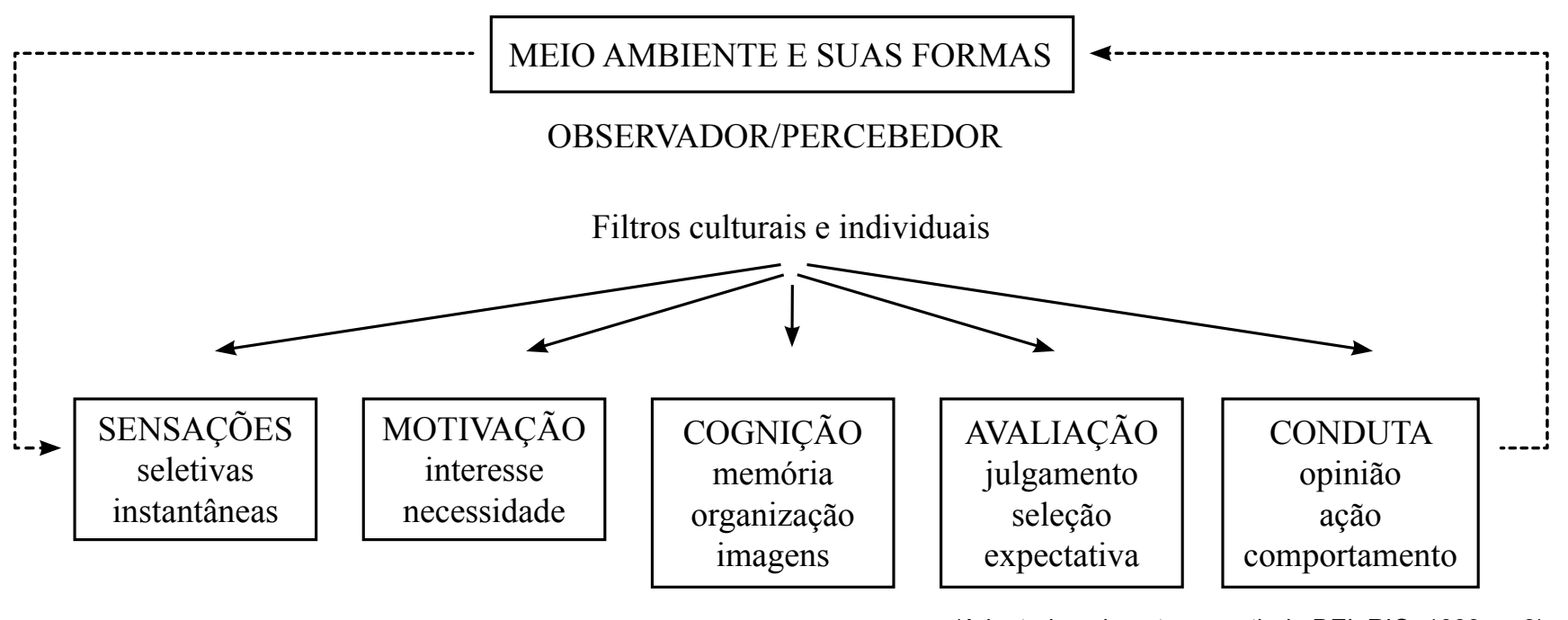

(Adaptado pelo autor a partir de DEL RIO, 1999, p. 3)

(...) a paisagem a partir da ordenação de dois ângulos diversos de visão: a vertical, objetiva que tem a paisagem como domínio que viabiliza a vida humana; a lateral, subjetiva que considera a paisagem enquanto espaço de ação ou contemplação. (TUAN, apud HOLZER, 1999, p.158)

O autor coloca o homem como figura-chave, indissociável do processo de reconhecimento desta.

Logo, conforme cita Cabral (1999), ao se realizar um estudo reflexivo sobre a valorização da paisagem a partir de uma perspectiva humanista, tem-se, indubitavelmente, que pensar além das formas que a compõem, dirigindo-se a atenção da pesquisa do visível para os fenômenos vividos na busca da compreensão da maneira pelas quais as pessoas partilham e se relacionam com essa paisagem.

\section{CONSIDERAÇÕES FINAIS}

A partir da história, percebe-se que há na Geografia uma multiplicidade de abordagens que se justapõem onde verdades não são absolutas e nas quais conhecimentos são constantemente superados, abrindo-se a cada momento novas leituras ou perspectivas sobre a compreensão da relação entre a sociedade e o meio em que se vive.
Objetivou-se com este artigo apresentar a Geografia Humanista enquanto perspectiva de estudo geográfica que, assim como todo o conhecimento geográfico, transformou-se ao longo do tempo, tendo sua estruturação discutida e reelaborada a partir do surgimento de novas idéias e debates.

Nesse sentido, um primeiro princípio a ser referenciado e destacado, em especial na Geografia, é o fato de que, embora haja um objeto comum, diferentes olhares, perspectivas, leituras e formas de pensamento interagem e tornam o conhecimento geográfico melhor e mais completo.

Falando da Geografia Humanista, de início essa perspectiva de estudo causou, e ainda causa em muitos, uma preocupação com uma redefinição da noção geográfica de paisagem, onde o homem encontra-se no centro não apenas como observador, mas sim como parte integrante da mesma.

No Brasil, os estudos pautados sobre a Geografia Humanista tomaram destaque a partir da década de 70 , período no qual trabalhos acerca dessa linha de pensamento são traduzidos e publicados no país, sendo esse movimento responsável, segundo Oliveira (2001, p. 14), pelo desencadeamento de um maior interesse, especialmente por parte dos geógrafos, pelo reconhecimento de como "(...) as pessoas percebem o seu redor, o seu meio 
ROCHA, S. A. Geografia Humanista: história, conceito e o uso da paisagem...

ambiente; aguçou a curiosidade em saber se a percepção geográfica variava e quanto; provocou, principalmente, um aumento de estudos e pesquisas sobre o assunto", contrapondo-se assim a uma quantificação estatística das relações.

Os trabalhos nessa linha prosseguiram, contudo de forma menos numerosa em relação a outras perspectivas de estudo geográfica, sendo, no entanto, destacável a produção de diversos trabalhos sobre percepção ambiental, o que é ainda mais popularizado com a tradução dos livros Topofilia e Espaço e lugar de Yi fu Tuan, realizadas respectivamente em 1980 e 1983, e a ampliação de discussões acadêmicas tanto em disciplinas vinculadas a cursos de graduação e pós-graduação quanto a pesquisas observadas em projetos específicos ou individuais.

Contudo, especialmente no Brasil, a Geografia Humanista ainda é discutida por um grupo que, proporcionalmente, ainda é reduzido em relação a outras perspectivas de estudo geográfico. Entender as paisagens a partir das percepções, ou seja, de um conjunto composto por sentimentos e valores, é um desafio que se apresenta dentro da Geografia, sendo fato que somente a partir de novos estudos, de novas discussões e debates, é que a Geografia Humanista vai se desenvolver mantendo a sua qualidade e ampliando os seus horizontes de conhecimento.

\section{REFERÊNCIAS}

AMORIM FILHO, Oswaldo Bueno. A formação do conceito de paisagem geográfica: os fundamentos clássicos. In: Encontro Interdisciplinar sobre o estudo da paisagem. Rio Claro, 1113 maio 1998. Cadernos paisagem, paisagens 3. Rio Claro: UNESP, 1998. p. 123-138.

BUTTIMER, Anne. Aprendendo o dinamismo do mundo vivido. In: CHRISTOFOLETTI, Antonio (Org.). Perspectivas da Geografia. São Paulo: Difel, 1982. p. 165-193.

CABRAL, Luiz Otávio. Bacia da Lagoa do Peri: sobre as dimensões da paisagem e seu valor. Florianópolis: Universidade Federal de Santa Catarina. Dissertação (Mestrado em Geografia). Departamento de Geociências, 1999.

CARLOS, Ana Fani Alessandri. A Geografia brasileira, hoje: algumas reflexões. Terra Livre, São Paulo, ano 18, v. 1 , n. 18, jan./ jun. 2002, p. 161-178.

CLAVAL, Paul. A revolução pós-funcionalista e as concepções atuais da Geografia. In: MENDONÇA, Francisco; KOZEL, Salete (Org.). Elementos de epistemologia da Geografia contemporânea. Curitiba: Ed. da UFPR, 2002. p.11-43.

As abordagens da Geografia cultural. In: CASTRO, Iná Elias de; GOMES, Paulo César da Costa; CORREAA, Roberto Lobato (Org.). Explorações geográficas: percursos no fim do século. Rio de Janeiro: Bertrand Brasil, 1997. p. $89-118$.

COBRA, Rubem Q. Edmund Husserl. Página de "Filosofia Contemporânea". Disponível em: <http://www.cobra.pages. nom.br>Acesso em: 9/12/2004.

COLLOT, Michel. Pontos de vista sobre a percepção das paisagens. Boletim de Geografia Teorética, v. 20, n. 39, p. 21-32, 1990.
DEL RIO, Vicente. Cidade da mente, cidade real: percepção ambiental e revitalização na área portuária do Rio de Janeiro. In: RIO, Vicente del; OLIVEIRA, Lívia de (Org.). Percepção ambiental a experiência brasileira. São Paulo: Studio Nobel, 1999.

ENTRIKIN, J. Nicholas. O Humanismo Contemporâneo em Geografia. Boletim Geografia Teorética, Rio Claro, v. 10, n. 19 p. 5-30, 1980.

GARNICA, A. V. M. Algumas notas sobre pesquisa qualitativa e fenomenologia. Interface: Comunicação, Saúde, Educação, v. 1, n. 1, 1997. p. 109-119.

HOLZER, Werther. A Geografia Humanista: sua trajetória de 1950 a 1990. Rio de Janeiro, 1992. Dissertação (Mestrado) Departamento de pós-graduação em Geografia da UFRJ.

A Geografia Humanista: uma revisão. Espaço e Cultura, Rio de Janeiro, UERJ/NEPEC, n. 3, p. 8-19, 1996.

. Paisagem, imaginário, identidade: alternativas para o estudo geográfico. In: ROSENDAHL, Zeny; CORREAA, Roberto Lobato (Org.). Manifestações da cultura no espaço. Rio de Janeiro: Ed. UERJ, 1999. p. 149-168.

. Uma discussão fenomenológica sobre os conceitos de paisagem e lugar, território e meio ambiente. Revista Território, v. 2, n. 3, p. 77-85, jul./ dez. 1997.

LOWENTHAL, David. Geografia, experiência e imaginação: em direção a uma nova epistemologia da Geografia. In: CHRISTOFOLETTI, Antonio (Org.). Perspectivas da Geografia. São Paulo: Difel, 1982. p. 101-130.

MAXIMIANO, Liz Abad. Considerações sobre o conceito de paisagem. RA'E GA, Curitiba, Ed. UFPR, n. 8, p. 83-91, 2004. 
ROCHA, S. A. Geografia Humanista: história, conceito e o uso da paisagem...

MEINIG, Donald W. O olho que observa: dez visões sobre a mesma cena. Espaço e cultura, UERJ, n. 13, p. 35-46, jan./jun. 2002.

MERLEAU-PONTY, Maurice. Fenomenologia da percepção. São Paulo: Martins Fontes, 1994.

OLIVEIRA, Lívia de. Percepção do meio ambiente e Geografia. In: OLAN - Ciência \& Tecnologia [arquivo de dados legíveis por máquina]. v.1, n. 2 nov. 2001. Rio Claro: Aleph, Engenharia e Consultoria Ambiental, 2001. p. 14-28.

RELPH, Edward. As bases fenomenológicas da Geografia. Geografia, v. 7, n. 4, p. 1-25, abr. 1975.

SANTOS, Milton. Metamorfoses do espaço habitado. São Paulo: Hucitec, 1997.

SAUER, Carl O. A morfologia da paisagem. In: CORREAA, Roberto Lobato; ROSENDAHL, Zeny (Org.). Paisagem, tempo e cultura. Rio de Janeiro: Ed. UERJ, 1998. p. 12-74.

SEABRA, Giovanni de Farias. Fundamentos e perspectivas da Geografia. João Pessoa: Editora Universitária UFPB, 1999.

SERPA, Ângelo. Percepção e fenomenologia: em busca de um método humanístico para estudos e intervenções do/no lugar. In: OLAN - Ciência \& Tecnologia [arquivo de dados legíveis por máquina]. v.1, n. 2 nov. 2001. Rio Claro: Aleph, Engenharia e Consultoria Ambiental, 2001. p. 29-61.

TUAN, Yi Fu. Espaço e lugar: a perspectiva da experiência. São Paulo: Difel, 1983.

Geografia Humanística. In: CHRISTOFOLETTI, Antonio (Org.). Perspectivas da Geografia. São Paulo: Difel, 1982. p. 143-164.

Topofilia: um estudo da percepção, atitudes e valores do meio ambiente. São Paulo: Difel, 1980.

VON ZUBEN, Newton Aquiles. Os caminhos da fenomenologia. Disponível em: <http://www.fae.unicamp.br/vonzuben/ caminhos.html> Acesso em: 20/11/2004.

YÁZIGI, Eduardo. A alma do lugar: turismo, planejamento e cotidiano em litorais e montanhas. São Paulo: Contexto, 2001. 